\title{
Acute Lung Injury: Prevention May Be the Best Medicine
}

\author{
John M Litell DO, Michelle Ng Gong MD, Daniel Talmor MD MPH, \\ and Ognjen Gajic MD MSc
}

\author{
Introduction \\ Background \\ Defining the Syndrome \\ Pathophysiologic Mechanisms \\ ALI as a Preventable Complication of Critical Illness \\ The Multiple-Hit Hypothesis \\ Research Challenges and Opportunities in ALI Prevention \\ Limitations of Interventional Trials in Critical Care \\ The Role of Multicenter Collaboration \\ Development of Strategies to Prevent ALI \\ Barrier 1: Risk Stratification: Development of the Lung Injury Prediction \\ Score \\ Barrier 2: Standardizing Best Practices: The Checklist for Lung Injury \\ Prevention \\ Barrier 3: Pharmacoprevention: Organizing Multicenter Clinical Trials \\ Summary
}

\begin{abstract}
Acute lung injury affects a subset of hospitalized patients but is not universal. This syndrome can substantially delay ventilator liberation, prolong intensive care unit (ICU) stay, and increase mortality. As with many critical illness syndromes, the available treatment options are limited in number and impact. Once a patient develops lung injury, the best known strategy is supportive care. Observational studies have identified potential risk factors and have suggested that the use and timing of certain critical care interventions may influence the likelihood of developing lung injury. These findings suggest that a well designed screening tool and the systematic application of best practices in critical care may limit the risk of lung injury. An effective prediction score may also facilitate enrollment in pharmacopreventive trials. Development of such tools is accelerated by multicenter collaboration. Key words: acute lung injury; mechanical ventilation; intensive care; critical illness; prevention. [Respir Care 2011;56(10):1546-1554. (C) 2011 Daedalus Enterprises]
\end{abstract}

Drs Litell and Gajic are affiliated with the Division of Pulmonary and Critical Care Medicine, Department of Medicine, Mayo Clinic, Rochester, Minnesota. Dr Gong is affiliated with the Division of Critical Care Medicine, Department of Medicine, Montefiore Medical Center, Albert Einstein College of Medicine, Bronx, New York. Dr Talmor is affiliated with the Department of Anesthesia, Critical Care, and Pain Medicine, Beth Israel Deaconess Medical Center, Harvard Medical School, Boston, Massachusetts.

Dr Gajic presented a version of this paper at the 26th New Horizons Symposium, "ARDS Update," at the 56th International Respiratory Congress of

\footnotetext{
the American Association for Respiratory Care, held December 6-9, 2010, in Las Vegas, Nevada.

The authors have disclosed no conflicts of interest.

Correspondence: John M Litell DO, Division of Pulmonary and Critical Care Medicine, Mayo Clinic, 200 First Street SW, Rochester MN 55905. E-mail: litell.john@mayo.edu.
}

DOI: $10.4187 /$ respcare. 01361 


\section{Introduction}

Acute lung injury and the acute respiratory distress syndrome (hereafter both referred to as ALI) are characterized by rapidly progressive hypoxic respiratory failure following various direct or indirect injuries to the pulmonary parenchyma or vasculature. This devastating complication of critical illness can increase mortality and prolong recovery for patients with a variety of presenting problems. As with many critical illness syndromes, the available treatments have limited efficacy once ALI is fully established. Despite progress in supportive care strategies and the understanding of certain clinical and molecular mechanisms implicated in ALI, comparatively little is known about the prevention of this challenging syndrome. ${ }^{1-3}$ In this review we will summarize ALI pathogenesis and discuss current efforts to identify and apply evidence-based lung injury prevention strategies.

\section{Background}

\section{Defining the Syndrome}

Unlike diseases with an identifiable microbiological or genetic trigger, ALI and ARDS are clinical syndromes defined by consensus among experts. The American-European Consensus Conference criteria, articulated in 1994, outline the features that distinguish ALI from other causes of pulmonary edema (Table 1). ${ }^{4}$ These include a radiographic pattern of diffuse bilateral infiltrates and an oxygenation defect that is not attributable to hydrostatic pulmonary edema, such as in heart failure. These criteria establish both a reasonably simple means of identifying ALI in the clinical setting and also standardize definitions for research purposes. Although widely implemented, the American-European Consensus Conference criteria do have some limitations, including a relatively poor correlation with post-mortem evidence of diffuse alveolar damage, which is thought to be a characteristic histologic feature of

Table 1. American-European Consensus Conference Criteria for Acute Lung Injury and Acute Respiratory Distress Syndrome

\begin{tabular}{|c|c|c|c|}
\hline & Chest Radiograph & $\begin{array}{l}\mathrm{P}_{\mathrm{aO}_{2}} / \mathrm{F}_{\mathrm{IO}_{2}} \\
(\mathrm{~mm} \mathrm{Hg})\end{array}$ & $\begin{array}{l}\text { Pulmonary Artery } \\
\text { Occlusion Pressure }\end{array}$ \\
\hline ALI & $\begin{array}{l}\text { Diffuse bilateral } \\
\text { infiltrates }\end{array}$ & $\leq 200$ & $\begin{aligned} \leq & 18 \mathrm{~mm} \mathrm{Hg} \text { or no clinical } \\
& \text { evidence of left atrial } \\
& \text { hypertension }\end{aligned}$ \\
\hline ARDS & $\begin{array}{l}\text { Diffuse bilateral } \\
\text { infiltrates }\end{array}$ & $\leq 300$ & $\begin{aligned} \leq & 18 \mathrm{~mm} \mathrm{Hg} \text { or no clinical } \\
& \text { evidence of left atrial } \\
& \text { hypertension }\end{aligned}$ \\
\hline
\end{tabular}

$\overline{\mathrm{ALI}}=$ acute lung injury

ARDS $=$ acute respiratory distress syndrome

(Adapted from Reference 4).
ALI. ${ }^{5}$ Also, by including only the $\mathrm{P}_{\mathrm{aO}_{2}} / \mathrm{F}_{\mathrm{IO}_{2}}$ the AmericanEuropean Consensus Conference criteria do not index oxygenation defects to modes of ventilation or PEEP level, which may limit their accuracy for individual patients. Although various alternative criteria have been proposed, none have been formally validated, and the AmericanEuropean Consensus Conference criteria are the starting point for any effort to standardize ALI research, prevention, and treatment strategies.

\section{Pathophysiologic Mechanisms}

In addition to these broad diagnostic criteria, a variety of mechanical, chemical, and biological insults can converge to give rise to the characteristic alveolocapillary membrane damage seen in ALI. Understanding these factors can guide investigators and bedside clinicians toward strategies that identify and reduce risk factors for progression to ALI.

Chemical injury-such as acid aspiration, smoke inhalation, or near-drowning - bacterial or viral pneumonia, and other directly acting biological insults can initiate the cascade of events that result in ALI. Consequently, early administration of appropriate antimicrobial agents and interventions to minimize aspiration are essential elements of lung protection. Platelet activation and secondary capture of neutrophils are known features of direct lung injury, but these are seen in systemic inflammatory states as well. Thus, indirect biological insults (eg, shock, sepsis, extrathoracic trauma, transfusion, pancreatitis) can also result in platelet activation and platelet-mediated neutrophil aggregation with multiple deleterious effects, including lung injury. ${ }^{6}$ Direct macroscopic injuries such as chest trauma or certain thoracic surgical procedures are also associated with ALI. ${ }^{7-10}$

Additionally, microscopic mechanical traumas have been implicated in the development of lung injury via effects on alveolocapillary membrane integrity. ${ }^{11}$ For example, alveolar overdistention from injurious mechanical ventilation and cyclic collapse at end-expiration result in strain and shear stresses in the alveoli. These can result in a selfperpetuating cascade of alveolocapillary membrane fracture and pulmonary inflammation progressing to altered pulmonary capillary permeability and worsened alveolar diffusion capacity. ${ }^{12}$ These processes converge clinically, manifesting as noncardiogenic pulmonary edema ${ }^{11,13}$ with impaired oxygen diffusion, intrapulmonary shunt, hypoxic respiratory failure, and the radiographic appearance of bilateral infiltrates.

There are 2 characteristic histopathologic phases of ALI. The early exudative phase involves diffuse alveolar damage due to widespread necrosis of type I pneumocytes, diffuse macrovascular injury, and influx of inflammatory cells and proteinaceous fluid into the alveoli and interstitium. This occurs in a heterogeneous fashion leading to lung regions with vastly different degrees of injury, which 


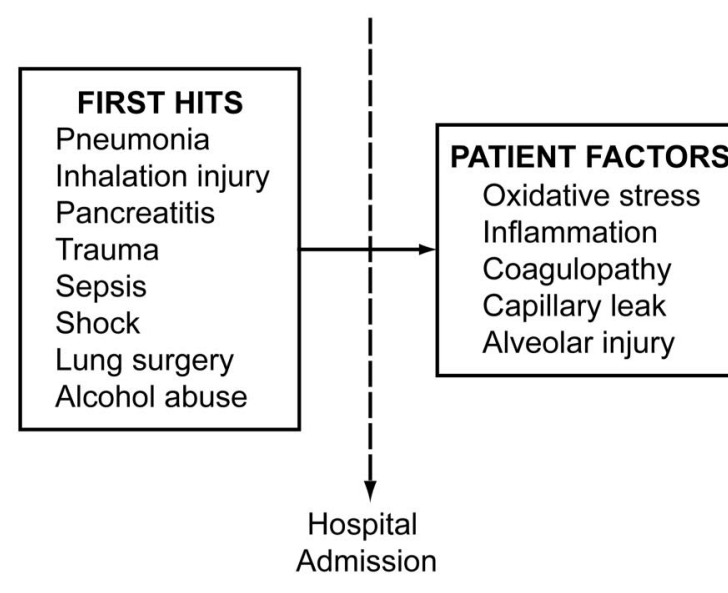

Fig. 1. Progression to acute lung injury (ALI).

has implications for safe ventilation strategies. ${ }^{12}$ These acute changes are followed by a fibroproliferative phase during which lung repair is manifested as proliferation of type II pneumocytes and fibroblasts. ${ }^{14}$

\section{ALI as a Preventable Complication of Critical Illness}

\section{The Multiple-Hit Hypothesis}

The development of cancer and cardiovascular disease are often described in terms of a multiple-hit hypothesis, wherein disease develops not from isolated risk factors but following an accumulation of predisposing features and subsequent insults. A similar framework can be employed to illustrate patients' progression to ALI (Fig. 1). The multiple-hit hypothesis for ALI describes patients at increased baseline risk due to epidemiologic background features plus their initial pulmonary or extrapulmonary problem. In isolation these may not lead directly to alveolar damage, but when combined with additive second hits the result is an increased risk of ALI.

The concept of second hits is supported in part by evidence linking variations in critical care delivery with an increased risk of lung injury. Iscimen and colleagues observed that delayed treatment of shock and infection were associated with an odds ratio of 3.55 for the development of ALI. ${ }^{15}$ Patients with shock require the rapid restoration of effective circulating volume, ideally targeted to clinically meaningful end points. Evidence of infection should prompt the early appropriate use of antimicrobials, either empirically or based on promptly available diagnostic studies such as radiographs or sputum Gram-stain results in mechanically ventilated patients. ${ }^{16,17}$ Implementation of early appropriate resuscitative care beginning in the emergency department, operating room, or hospital ward as soon as shock and infection are recognized - a cornerstone of critical care-also appears to be an essential ALI prevention strategy. Later interventions may also impact ALI risk. For example, after the acute phase of resuscitation, accumulating evidence suggests that a conservative fluid management strategy can attenuate the risk of lung injury. ${ }^{18,19}$

Whereas elements of the therapeutic approach described above are employed because of physiologic rationale or indirect evidence of benefit, some critical care interventions have been associated with relatively robust data regarding their role in ALI prevention. For example, mechanical ventilation with a low-tidal-volume strategy (6$8 \mathrm{~mL} / \mathrm{kg}$ predicted body weight) is associated with a lower incidence of lung injury and overall mortality. ${ }^{20}$ Applying this strategy universally in mechanically ventilated patients may reduce the aggregate risk of ALI. In our practice we have found that a multidisciplinary educational initiative combined with electronic surveillance for injurious tidal volumes and automated provider alerts can limit patients' exposure to unsafe ventilation and have been associated with lower mortality. ${ }^{21}$

Transfusion-related ALI, which is the leading cause of death after blood-product administration, is defined as ALI occurring within 6 hours of blood-product transfusion, in the absence of other risk factors (eg, sepsis, aspiration, or lung contusion). If other risk factors are present when ALI develops within 6 hours, the term "possible transfusionrelated ALI" is employed.22 Transfusion-related ALI may be due in part to overly liberal administration of blood products, which are often given without reference to evidence-based guidelines. ${ }^{23}$ At Mayo Clinic we have found 
that relatively simple solutions can mitigate this problem. For example, the addition of decision-support prompts to the computerized order-entry screen for blood-product administration was associated with 1,000 fewer transfusions over a 3-month study period, and reduced incidence of transfusion-related ALI and other complications from $6.1 \%$ to $2.7 \% .{ }^{24}$

Additional data also suggest that blood products from alloimmunized donors-particularly parous womenconfer a particularly high risk of transfusion-related ALI. ${ }^{25,26}$ A subsequent shift in our procurement protocol to male-only donors for plasma and platelets was associated with a sustained decrease in transfusion-related ALI. In 2006 the American Association of Blood Banks recommended limiting both unnecessary transfusions and the collection of high-volume plasma components from donors with known leukocyte alloimmunization. ${ }^{27}$ Subsequently the United States Food and Drug Administration reported a decrease in both transfusion-related-ALI-related deaths and plasma transfusions, while the rate of red-cell transfusions remained constant. ${ }^{28}$

It is essential to recognize that ALI is usually not present at the time of initial hospitalization and is far from ubiquitous in patients with a variety of presenting critical illnesses. In a prospective observational study in 2007, Ferguson and colleagues found that only $7.5 \%$ of hospitalized patients with sepsis, $1.3 \%$ with pancreatitis, $10 \%$ with pneumonia, and $16 \%$ with witnessed aspiration developed ALI. ${ }^{29}$ In a recent multicenter study, Gajic and colleagues found similar numbers. The large cohort size in that study-over 5,000 patients—also produced intriguing findings about the frequency of ALI in patients with various primary diagnoses. Smoke inhalation, for example, was a substantially more common risk factor than pancreatitis and other conditions more commonly associated with ALI. ${ }^{30}$ Such multicenter studies are essential to identifying these types of patterns, allowing us to question or revise established notions. Other investigators have identified apparent risk modifiers-elements associated with both increased (alcohol use, chemotherapy) and decreased (diabetes) risk of ALI development. 15,31,32

Only a subset of hospitalized patients at epidemiologic risk of ALI goes on to develop the syndrome; the timing and consistency of certain critical care interventions appear to modify that risk. This suggests that ALI results, at least in part, from a pattern of risk factors and second insults, some of which are directly related to ICU management. Viewing the development of ALI in terms of multiple hits and risk modifiers can guide daily clinical management and research on prevention and treatment, and also has implications for the design of health services delivery in critical care. Attention to these areas may be the most effective way to limit the incidence, morbidity, and mortality associated with ALI.

\section{Research Challenges and Opportunities in ALI Prevention}

\section{Limitations of Interventional Trials in Critical Care}

Although the last decade has featured a surge in collaborative research initiatives in critical care, ${ }^{33}$ even well designed trials evaluating mechanistic treatments applied after the onset of critical illness have been overwhelmingly negative. ${ }^{34}$ The complexity of critical illness and ICU interventions renders them extremely difficult to study in a reasonably controlled fashion, and mechanistic interventions in these patients seem unlikely to produce a measurable impact. For ALI and other hospital-acquired conditions, enrollment of patients in clinical trials after the onset of organ failures and critical illness syndromes limits available interventions to state-of-the-art supportive care. In these patients the presence of ALI can be viewed as a marker for some combination of established illness and various critical care interventions. A preventive strategy, addressing early identification of at-risk patients and consistent application of evidence-based therapy, may be more fruitful. Epidemiologic evidence suggests that early syndrome recognition and improvements in healthcare delivery are associated with a measurable decrease in the incidence of ALI.

In a recent population-based retrospective cohort study in Olmstead County, Minnesota, Li and colleagues found a decrease in the incidence of hospital-acquired ARDS from 82 to 39 cases per 100,000 person-years during the 8-year study period, despite a parallel increase in admissions and severity of illness. ${ }^{35}$ They carefully described associated changes in the ICU care-delivery model during the study period (Fig. 2). Although causality cannot be claimed from that association, the strong implication is that global improvements in care delivery may limit the development of syndromes such as ALI that complicate critical illness.

Indeed, the universal daily care plan for ICU patients incorporates various broadly accepted preventive strategies. Gastric-acid suppressants are administered to prevent lethal hemorrhage; heparin and mechanical compression devices are used to prevent venous thromboembolism; oral care and patient positioning are employed to prevent pneumonia in ventilated patients; intravascular and urinary catheters are removed to limit the risk of nosocomial infection. Given that ALI develops after hospitalization in certain critically ill patients with a predictable pattern of risk factors, it is conceivable to approach ALI as another potentially preventable complication of critical illness.

\section{The Role of Multicenter Collaboration}

In light of data suggesting that the incidence of ALI-as with other preventable complications of critical care-may 


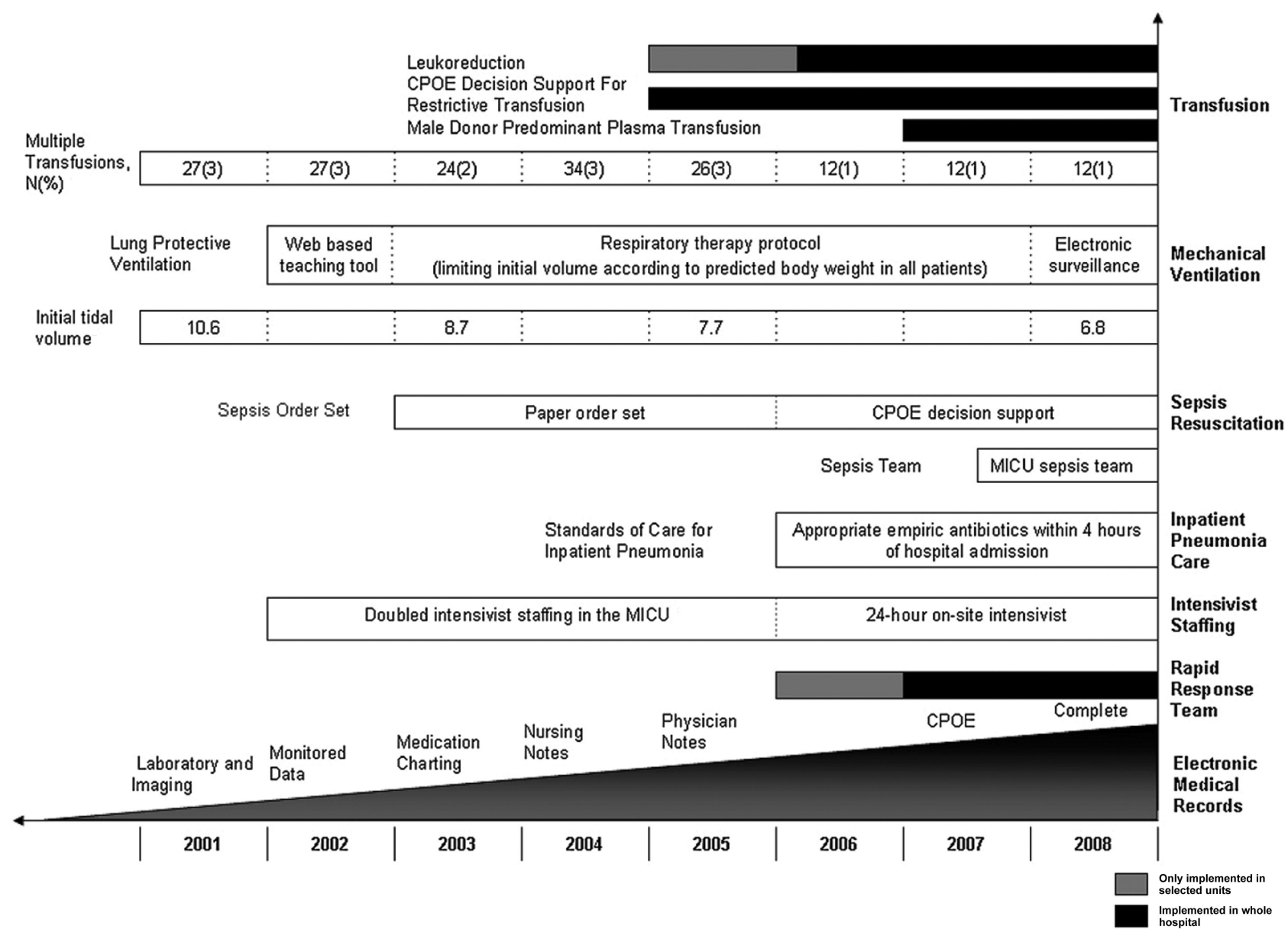

Fig. 2. Changes in intensive care during the study period. (From Reference 35, with permission.)

be reduced by attention to care delivery, a multicenter collaborative group has set out to identify best practices in ALI prevention and to design systems that support their consistent application. This multicenter approach is particularly important given the declining incidence of ALI in many institutions, to a point where any single center cannot provide a sufficient number of participants to draw meaningful conclusions. The United States Critical Illness and Injuries Trials Group is a research community composed of investigators from emergency medicine, trauma surgery, anesthesiology, pediatrics, and pulmonary/critical care medicine, among others. To identify and overcome barriers to optimal ALI care, a section within this group is coordinating joint studies with representatives from more than 20 institutions.

\section{Development of Strategies to Prevent ALI}

The development of strategies to prevent ALI involves overcoming 3 major barriers:

- First, effective screening tools are required to identify with a reasonable degree of accuracy those patients at high risk for development of ALI; it must also be possible to make this identification early, ideally at the time of first presentation to the hospital.

- Second, knowledge translation and quality-improvement strategies must be employed to minimize practice variation and under-utilization of clinical practices that have been shown to influence ALI development and subsequent patient outcomes.

- Third, preliminary data suggesting the existence of safe and effective pharmacologic therapies to prevent ALI must be tested in a rigorous fashion.

These barriers are interrelated; the ability to effectively implement practice standardization and to study novel therapies is contingent upon the availability of a reliable prediction tool.

\section{Barrier 1: Risk Stratification: Development of the Lung Injury Prediction Score}

Historically, ALI studies have focused exclusively on patients admitted to the ICU. 25,31,32,36 This approach, though 
Table 2. Lung Injury Prediction Scoring System

\begin{tabular}{|c|c|}
\hline & Points \\
\hline \multicolumn{2}{|l|}{ Presenting Conditions } \\
\hline Shock & 2 \\
\hline Aspiration & 2 \\
\hline Sepsis & 1 \\
\hline Pneumonia & 1.5 \\
\hline \multicolumn{2}{|l|}{ High-risk surgery } \\
\hline Spinal & 1 \\
\hline Acute abdominal & 2 \\
\hline Cardiac & 2.5 \\
\hline Aortic & 3.5 \\
\hline \multicolumn{2}{|l|}{ High-risk trauma } \\
\hline Multiple fractures & 1.5 \\
\hline Lung contusion & 1.5 \\
\hline Near drowning & 2 \\
\hline Smoke inhalation & 2 \\
\hline Brain injury & 2 \\
\hline \multicolumn{2}{|l|}{ Risk Modifiers } \\
\hline Alcohol abuse & 1 \\
\hline Body mass index $>30 \mathrm{~kg} / \mathrm{m}^{2}$ & 1 \\
\hline Hypoalbuminemia & 1 \\
\hline Chemotherapy & 1 \\
\hline $\mathrm{F}_{\mathrm{IO}_{2}}>0.35(>4 \mathrm{~L} / \mathrm{min})$ & 2 \\
\hline Respiratory rate $>30$ breaths $/ \mathrm{min}$ & 1.5 \\
\hline $\mathrm{S}_{\mathrm{pO}_{2}}<95 \%$ & 1 \\
\hline $\mathrm{pH}<7.35$ & 1.5 \\
\hline Diabetes & -1 \\
\hline
\end{tabular}

$\overline{\text { (Adapted from References } 37 \text { and 38.) }}$

it provided essential early data, has limited the degree to which at-risk patients can be systematically identified and protected regardless of their location in the hospital. For example, respiratory failure and the need for mechanical ventilation are frequently the reason for ICU admission (often followed shortly by the diagnosis of lung injury), but the biological underpinnings of ALI begin much earlier. ${ }^{25,37}$ Equally importantly, a substantial number of patients with predisposing conditions are never admitted to the ICU and are thus never enrolled in ICU-based studies, which limits our understanding of why these patients do not develop ALI. Lung injury is rarely present at the time of admission, unless the patient is transferred from a referring hospital, and fewer than $1 \%$ of patients admitted to the hospital without any risk factors develop ALI. ${ }^{38}$ A riskstratification tool that effectively filters patients with a higher likelihood of ALI development would both maximize and simplify enrollment into lung injury prevention studies.

A recent prospective multicenter observational cohort study arranged by the United States Critical Illness and Injuries Trials Group validated the lung injury prediction score, which is based on simple variables available at the time of first presentation (Table 2). A score of $\geq 4$ pre-

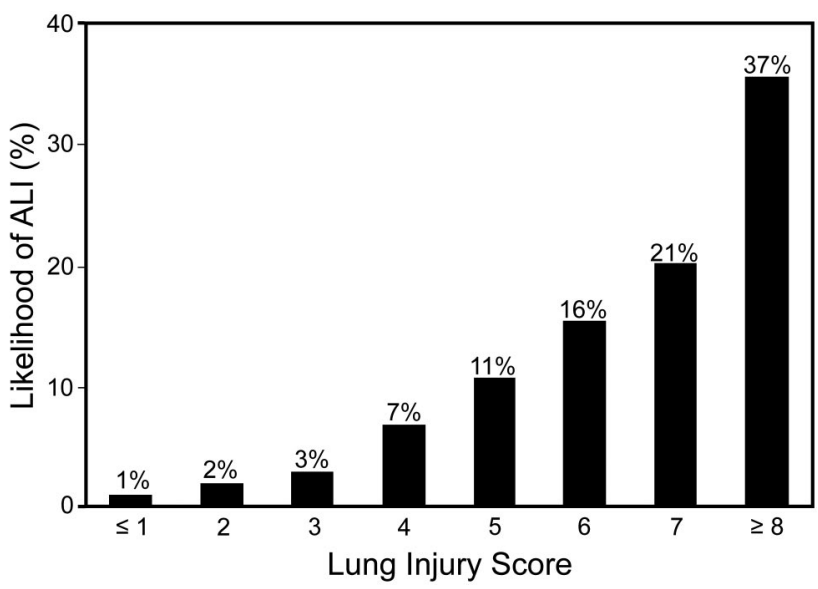

Fig. 3. Lung injury prediction score versus likelihood of acute lung injury. (From Reference 30.)

dicted ALI development with $69 \%$ sensitivity and $78 \%$ specificity (area under the curve 0.8) ${ }^{30}$ (Fig. 3). By substantially narrowing enrollment to this cohort of patients at highest risk, this simple prediction score makes the development of mechanistic studies and prevention trials far more feasible. Identifying patients at high risk for ALI early in their admission (in the operating room or emergency department rather than after ICU arrival) provides a precious and otherwise limited opportunity to prevent subsequent complications. Extending the reach of ALI prevention studies beyond the walls of the ICU also acknowledges that critical care is a multidisciplinary continuum and that critical illness disregards traditional hospital boundaries. The lung injury prediction score studies take this into account, facilitating a more practical, interdisciplinary, and patient-centered approach to acute care.

Another notable outcome of this multicenter collaboration has been the ability to determine more accurately the risk of ALI development given certain known predisposing conditions. One example is smoke inhalation-a relatively rare entity in any one institution-which has a far higher chance of contributing to ALI than sepsis or pancreatitis, which are 2 more commonly encountered risk factors (Fig. 4). The systematic application of insights such as this can alert clinicians to an increased risk of ALI even in patients with relatively rare pathology, triggering a more uniform application of early prevention strategies. That said, an early-warning system for ALI risk derived from the lung injury prediction score is useful only insofar as it triggers a consistent clinical response, incorporating the routine application of evidence-based critical care practices.

\section{Barrier 2: Standardizing Best Practices: The Checklist for Lung Injury Prevention}

The multiple-hit hypothesis described earlier highlights how certain evidence-based strategies in critically ill pa- 


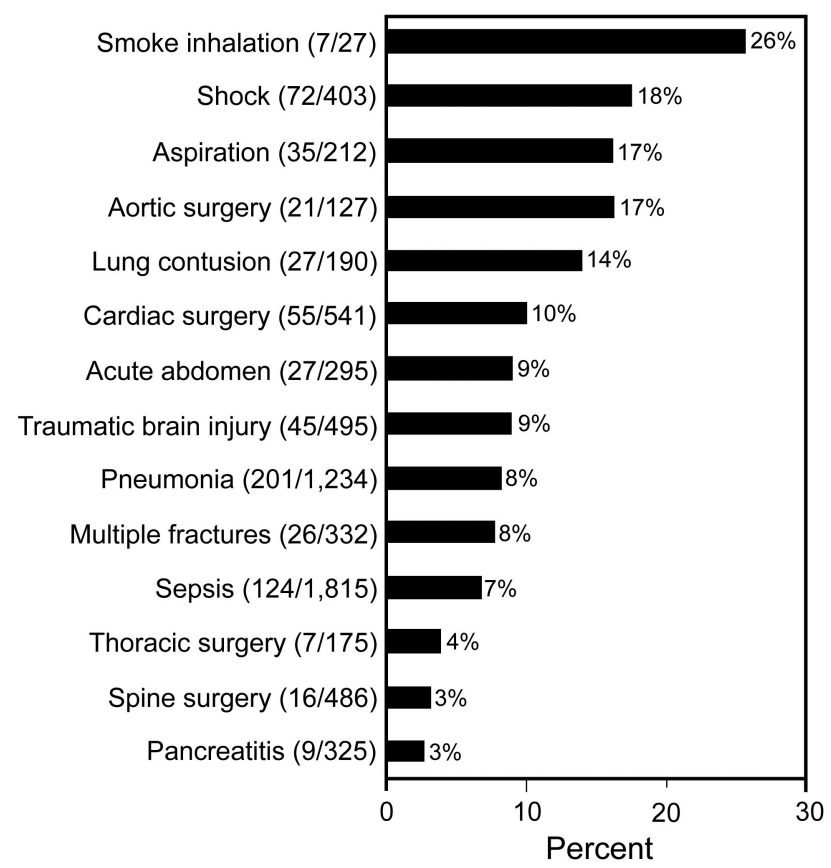

Fig. 4. Risk of acute lung injury with predisposing conditions. (Adapted from Reference 30.)

tients may attenuate their risk of developing ALI. The challenge for clinical investigators is to marshal the knowledge-translation and quality-improvement resources necessary to apply these strategies consistently and as early as possible in patients at risk.

While delayed treatment of shock and infection have a demonstrable association with increased risk of ALI, other critical care interventions, although not yet proven, may also play a role. For example, although limited data suggest that early noninvasive ventilation (NIV) can reduce the intubation rate in high-risk patients, ${ }^{39}$ NIV can also inappropriately delay intubation in patients with substantial disease burden. Although the use of NIV in ALI has not been evaluated in randomized trials, ${ }^{3}$ it is generally known that NIV for dyspneic patients must be implemented early and reassessed frequently to prevent delayed intubation and the dangerous consequences of respiratory failure. ${ }^{40}$ This is especially important in ALI, as up to $50 \%$ of patients with established lung injury may fail NIV. ${ }^{40}$ For patients requiring intubation, care should be taken to minimize the risk of acid aspiration. This is perhaps best accomplished by rapid-sequence induction supervised by an experienced provider ${ }^{41}$ and administration of $\mathrm{H} 2$ blockers throughout the course of mechanical ventilation. Potential practice standards such as these, if used consistently in patients at high risk of ALI, may have a protective effect.

In light of the evidence and experiences described above, the lung injury prevention subgroup of the United States Critical Illness and Injuries Trials Group is developing a bedside checklist for lung injury prevention that incorpo-
Table 3. Proposed Checklist for Lung Injury Prevention*

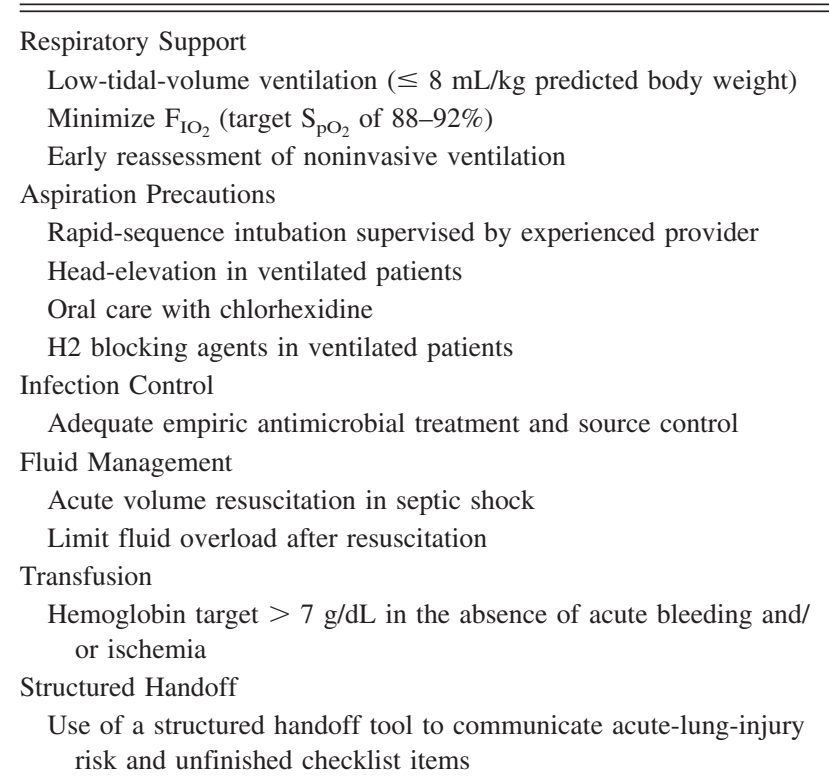

* These items represent evidence-based practices shown to generally benefit critically ill patients. If applied judiciously and early, these items may mitigate the risk of developing lung injury.

rates evidence-based strategies hypothesized to minimize the subsequent risk of ALI (Table 3). Although the ability to prevent ALI is controversial, all elements of this checklist represent evidence-based practices shown to benefit critically ill patients generally, and most are standard practices for patients admitted to the ICU. If applied judiciously and early to patients with a high lung injury prediction score who have not yet developed ALI, we hypothesize that the items on this list will decrease the risk of developing lung injury. Delivery of the checklist, in paper or electronic form, will be triggered by a high lung injury prediction score and will occur as early as possible in the hospitalization, typically in the emergency department, operating room, or early after ICU arrival. The list will highlight interventions relevant to that patient's clinical condition and is designed to follow a patient throughout their hospital course.

\section{Barrier 3: Pharmacoprevention: Organizing Multicenter Clinical Trials}

Preclinical evidence indicates that ALI can be attenuated by therapies targeting the oxidative, inflammatory, and procoagulant cascades involved in the pathophysiologic response to tissue injury. Platelet aggregation and platelet-neutrophil interaction in injured lung tissue are histologic features of the alveolar damage seen in ALI. Preclinical data have shown that inhibition of platelet ac- 
tivation and platelet-neutrophil aggregates is associated with impressive reductions in lung injury caused by acid aspiration and sepsis. ${ }^{6}$ In a population-based cohort in Olmstead County, Minnesota, the use of prehospital aspirin was associated with a reduced incidence of ALI. ${ }^{42}$ Our lung injury prevention subgroup is currently enrolling patients in a pilot multicenter prospective randomized trial involving prophylactic aspirin in patients at high risk for ALI.

Aerosolized unfractionated heparin and $\mathrm{N}$-acetylcysteine attenuate lung injury in mechanically ventilated adult patients after smoke inhalation. ${ }^{43,44}$ Other anti-inflammatory and anti-oxidant agents, such as curcumin, are also under investigation for ALI prevention. ${ }^{45,46}$ Additionally, $\beta_{2}$ adrenoreceptor agonists have been evaluated for their effects on lung vascular permeability and pro-surfactant effects. ${ }^{47}$ High-dose systemic corticosteroids were ineffective in preventing lung injury and were associated with worse outcomes in patients with septic shock. ${ }^{48}$ However, accumulating evidence suggests that inhaled steroids in patients at high risk may offer a preventive benefit. ${ }^{49}$ In response to those data, the lung injury prevention subgroup is organizing a multicenter evaluation of nebulized budesonide in patients at high risk for ALI development. Subsequent protocols may include other agents mentioned above.

Each of these interventions is associated with only mild adverse effects and their impact may be more potent if limited to patients at highest risk. We hope that a reliable lung injury prediction score will facilitate these types of investigations by focusing preventive strategies on the most vulnerable patient cohort.

\section{Summary}

Although acute lung injury is not a universal complication of critical illness, when it occurs, it can amplify shortterm and long-term debility. A multiple-hit model of ALI development, supported by observational data, offers a useful framework for designing and evaluating ALI prevention studies. Multicenter collaboration is essential to this process and is facilitated by the availability of a validated prediction score. Deploying this ALI prediction scoring system in the clinical environment may enable automated ALI surveillance and allow preventive action at the earliest possible point. This approach has implications for other critical illness syndromes and for the design of electronic medical record systems and health services delivery in critical care.

\section{REFERENCES}

1. Meade MO, Jacka MJ, Cook DJ, Dodek P, Griffith L, Guyatt GH. Survey of interventions for the prevention and treatment of acute respiratory distress syndrome. Crit Care Med 2004;32(4):946-954.
2. Matthay MA, Zimmerman GA, Esmon C, Bhattacharya J, Coller B, Doerschuk CM, et al. Future research directions in acute lung injury: summary of a National Heart, Lung, and Blood Institute working group Am J Respir Crit Care Med 2003;167(7):1027-1035.

3. Levitt JE, Matthay MA. The utility of clinical predictors of acute lung injury: towards prevention and earlier recognition. Expert Rev Respir Med 2010;4(6):785-797.

4. Bernard GR, Artigas A, Brigham KL, Carlet J, Falke K, Hudson L, et al. The American-European Consensus Conference on ARDS. Definitions, mechanisms, relevant outcomes, and clinical trial coordination. Am J Respir Crit Care Med 1994;149(3 Pt 1):818-824.

5. Esteban A, Fernández-Segoviano P, Frutos-Vivar F, Aramburu JA, Nájera L, Ferguson ND, et al. Comparison of clinical criteria for the acute respiratory distress syndrome with autopsy findings. Ann Intern Med 2004;141(6):440-445.

6. Zarbock A, Singbartl K, Ley K. Complete reversal of acid-induced acute lung injury by blocking of platelet-neutrophil aggregation. J Clin Invest 2006;116(12):3211-3219.

7. Navarrete-Navarro $P$, Rivera-Fernández R, Rincón-Ferrari MD, García-Delgado M, Muñoz A, Jiménez JM, Ortega FJ. Early markers of acute respiratory distress syndrome development in severe trauma patients. J Crit Care 2006;21(3):253-258.

8. Laudi S, Donaubauer B, Busch T, Kerner T, Bercker S, Bail H, et al. Low incidence of multiple organ failure after major trauma. Injury 2007;38(9):1052-1058.

9. Canet J, Gallart L, Gomar C, Paluzie G, Vallès J, Castillo J, et al; ARISCAT Group. Prediction of postoperative pulmonary complications in a population-based surgical cohort. Anesthesiology 2010; 113(6):1338-1350.

10. Grichnik K, D'Amico T. Acute lung injury and acute respiratory distress syndrome after pulmonary resection. Semin Cardiothorac Vasc Anesth 2004;8(4):317-334.

11. Gajic O, Lee J, Doerr CH, Berrios JC, Myers JL, Hubmayr RD. Ventilator-induced cell wounding and repair in the intact lung. Am J Respir Crit Care Med 2003;167(8):1057-1063.

12. Moloney ED, Griffiths MJD. Protective ventilation of patients with acute respiratory distress syndrome. Br J Anaesth 2004;92(2):261270.

13. Ware LB, Matthay MA. The acute respiratory distress syndrome. N Engl J Med 2000;342(18):1334-1349.

14. Lucas R, Verin AD, Black SM, Catravas JD. Regulators of endothelial and epithelial barrier integrity and function in acute lung injury. Biochem Pharmacol 2009;77(12):1763-1772.

15. Iscimen R, Cartin-Ceba R, Yilmaz M, Khan H, Hubmayr RD, Afessa $\mathrm{B}$, et al. Risk factors for the development of acute lung injury in patients with septic shock: an observational cohort study. Crit Care Med 2008;36(5):1518-1522.

16. Matsushima A, Tasaki O, Shimizu K, Tomono K, Ogura H, Shimazu $\mathrm{T}$, et al. Preemptive antibiotic treatment based on gram staining reduced the incidence of ARDS in mechanically ventilated patients. J Trauma 2008;65(2):309-315.

17. Kumar A, Roberts D, Wood KE, Light B, Parrillo JE, Sharma S, et al. Duration of hypotension before initiation of effective antimicrobial therapy is the critical determinant of survival in human septic shock. Crit Care Med 2006;34(6):1589-1596.

18. Wheeler AP, Bernard GR, et al. Pulmonary-artery versus central venous catheter to guide treatment of acute lung injury. N Engl J Med 2006;354(21):2213-2224.

19. Murphy CV, Schramm GE, Doherty JA, Reichley RM, Gajic O, Afessa B, et al. The importance of fluid management in acute lung injury secondary to septic shock. Chest 2009;136(1):102-109.

20. Ventilation with lower tidal volumes as compared with traditional tidal volumes for acute lung injury and the acute respiratory distress 
syndrome. The Acute Respiratory Distress Syndrome Network. N Engl J Med 2000;342(18):1301-1308.

21. Yilmaz M, Keegan MT, Iscimen R, Afessa B, Buck CF, Hubmayr $\mathrm{RD}$, Gajic O. Toward the prevention of acute lung injury: protocolguided limitation of large tidal volume ventilation and inappropriate transfusion. Crit Care Med 2007;35(7):1660-1666.

22. Kleinman S, Caulfield T, Chan P, Davenport R, McFarland J, McPhedran S, et al. Toward an understanding of transfusion-related acute lung injury: statement of a consensus panel. Transfusion 2004;44(12): 1774-89.

23. Croce MA, Tolley EA, Claridge JA, Fabian TC. Transfusions result in pulmonary morbidity and death after a moderate degree of injury. J Trauma 2005;59(1):19-23.

24. Rana R, Afessa B, Keegan MT, Whalen FX Jr, Nuttall GA, Evenson LK, et al. Evidence-based red cell transfusion in the critically ill: quality improvement using computerized physician order entry. Crit Care Med 2006;34(7):1892-1897.

25. Khan H, Belsher J, Yilmaz M, Afessa B, Winters JL, Moore SB, et al. Fresh-frozen plasma and platelet transfusions are associated with development of acute lung injury in critically ill medical patients. Chest 2007;131(5):1308-1314.

26. Gajic O, Rana R, Winters JL, Yilmaz M, Mendez JL, Rickman OB, et al. Transfusion-related acute lung injury in the critically ill: prospective nested case-control study. Am J Respir Crit Care Med 2007; 176(9):886-891

27. American Association of Blood Banks. Transfusion-related acute lung injury. Bethesda, MD: November 3, 2006; Association Bulletin 06-07.

28. US Food and Drug Administration. Fatalities reported to FDA following blood collection and transfusion: annual summary for fiscal year 2009. http://www.fda.gov/BiologicsBloodVaccines/ SafetyAvailability/ReportaProblem/TransfusionDonationFatalities/ ucm204763.htm. Accessed August 9, 2011.

29. Ferguson ND, Frutos-Vivar F, Esteban A, Gordo F, Honrubia T, Penuelas $\mathrm{O}$, et al. Clinical risk conditions for acute lung injury in the intensive care unit and hospital ward: a prospective observational study. Crit Care 2007;11(5):R96.

30. Gajic O, Dabbagh O, Park PK, Adesanya A, Chang SY, Hou P, et al. Early identification of patients at risk of acute lung injury: evaluation of lung injury prediction score in a multicenter cohort study. Am J Respir Crit Care Med 2011;183(4):462-470.

31. Moss M, Bucher B, Moore FA, Moore EE, Parsons PE. The role of chronic alcohol abuse in the development of acute respiratory distress syndrome in adults. JAMA 1996;275(1):50-54.

32. Moss M, Guidot DM, Steinberg KP, Duhon GF, Treece P, Wolken $\mathrm{R}$, et al. Diabetic patients have a decreased incidence of acute respiratory distress syndrome. Crit Care Med 2000;28(7):2187-2192.

33. Ely EW, Bernard GR. Transfusions in critically ill patients. N Engl J Med 1999;340(6):467-468

34. Ospina-Tascon GA, Buchele GL, Vincent JL. Multicenter, randomized, controlled trials evaluating mortality in intensive care: doomed to fail? Crit Care Med 2008;36(4):1311-1322.
35. Li G, Malinchoc M, Cartin-Ceba R, Venkata CV, Kor DJ, Peters SG, et al. Eight-year trend of acute respiratory distress syndrome: a population-based study in Olmsted County, Minnesota. Am J Respir Crit Care Med 2011;183(1):59-66.

36. Acute lung injury and the acute respiratory distress syndrome in Ireland: a prospective audit of epidemiology and management. Crit Care 2008;12(1):R30.

37. Gajic O, Afessa B, Thompson BT, Frutos-Vivar F, Malinchoc M, Rubenfeld GD, et al. Prediction of death and prolonged mechanical ventilation in acute lung injury. Crit Care 2007;11(3):R53.

38. Trillo-Alvarez C, Cartin-Ceba R, Kor DJ, Kojicic M, Kashyap R, Thakur $\mathrm{S}$, et al. Acute lung injury prediction score: derivation and validation in a population based sample. Eur Respir J 2011;37(3): 604-609.

39. Squadrone V, Massaia M, Bruno B, Marmont F, Falda M, Bagna C, et al. Early CPAP prevents evolution of acute lung injury in patients with hematologic malignancy. Intensive Care Med 2010;36(10):16661674.

40. Agarwal R, Aggarwal AN, Gupta D. Role of noninvasive ventilation in acute lung injury/acute respiratory distress syndrome: a proportion meta-analysis. Respir Care 2010;55(12):1653-1660.

41. Beck-Schimmer B, Bonvini JM. Bronchoaspiration: incidence, consequences and management. Eur J Anaesthesiol 2011;28(2):78-84.

42. Erlich JM, Talmor DS, Cartin-Ceba R, Gajic O, Kor DJ. Pre-hospitalization anti-platelet therapy is associated with a reduced incidence of acute lung injury: a population-based cohort study. Chest 2011; 139(2):289-95

43. Jepsen S, Herlevsen P, Knudsen P. Antioxidant treatment with Nacetylcyesteine during adult respiratory distress syndrome: a prospective randomized placebo controlled study. Crit Care Med 1992; 20(7):819-923.

44. Miller AC, Rivero A, Ziad S, Elamin EM, Smith DJ. Influence of nebulized unfractionated heparin and $\mathrm{N}$-acetylcysteine in acute lung injury after smoke inhalation injury. J Burn Care Res 2009;30(2): 249-256.

45. Bhatia M, Moochhala S. Role of inflammatory mediators in the pathophysiology of acute respiratory distress syndrome. J Pathol 2004;202(2):145-156.

46. Davreux CJ, Soric I, Nathens AB, Watson RW, McGilvray ID, Suntres $\mathrm{ZE}$, et al. N-acetyl cysteine attenuates acute lung injury in the rat. Shock 1997;8(6):432-438.

47. Perkins GD, McAuley DF, Thickett DR, Gao F. The Beta Agonist Lung Injury Trial (BALTI) a randomised placebo controlled clinical trial. Am J Respir Crit Care Med 2005;173(3):281-287.

48. Bone RC, Fisher CJ Jr, Clemmer TP, Slotman GJ, Metz CA. Early methylprednisolone treatment for septic syndrome and the adult respiratory distress syndrome. Chest 1987;92(6):1032-6.

49. Reade MC, Milbrandt EB. Is there evidence to support a phase II trial of inhaled corticosteroids in the treatment of incipient and persistent ARDS? Crit Care Resusc 2007;9(3):276-285. 